Running Head: EARLY PARENT INVOLVEMENT IN STEM

\title{
Feasibility of Behavior Change Techniques to Increase Parent Involvement in STEM with Young Children Experiencing Poverty
}

Tricia A. Zucker', Gloria Yeomans-Maldonado', Michael Assel', Cheryl McCallum², Cindy Elias', John M. Swint ${ }^{3}$, Lincy Lal ${ }^{3}$

'Children's Learning Institute, Department of Pediatrics at University of Texas Health Science Center at Houston

${ }^{2}$ Children's Museum Houston

${ }^{3}$ Department of Management, Policy and Community Health at University of Texas School of Public Health University of Texas Health Science Center-Houston

\begin{abstract}
Author Note
Tricia Zucker ORCID ID: https://orcid.org/0000-0003-3707-4946
\end{abstract}

Research reported in this publication was supported by Advancing Informal STEM Learning division of the National Science Foundation under award number 1811356. We are particularly grateful to Gisela Trevino and the informal science educators at the Children's Museum Houston for her work in ensuring these treatments were addressed the needs of this culturally and linguistically diverse sample.

Correspondence concerning this article should be sent to Tricia Zucker at 7000 Fannin St., 2400, Houston, TX 77030. Tricia.Zucker@uth.tmc.edu 
Students experiencing poverty have fewer opportunities for informal science, technology, engineering and math (STEM) learning outside of school (National Research Council [NRC], 2009) with opportunity gaps in preschool and elementary grades (e.g., Bruyere et al., 2009). This is problematic because early STEM interest can lead to pursuit of STEM careers and engagement in everyday science across the lifespan (e.g., NRC, 2015; Wang \& Degol, 2013). As early as preschool, families provide pathways for STEM engagement (e.g., Pattison et al., 2020). This study examined a pre-kindergarten (pre-k) program called Teaching Together (TT) STEM designed to increase parent involvement in STEM learning using educational family events and text messages. Meta-analyses show that interactive family education events produce small improvements in children's academic outcomes (Grindal et al., 2016; Milner-Bolotin \& Marotto, 2018). Although intensive parent coaching produces larger effects, this is high cost (e.g., Knight et al., 2020). Thus, this study added other lower cost techniques (STEM kits and incentives) to examine potential benefits for parent involvement.

\section{Early Parent Involvement}

Parent involvement is essential to building a STEM learning ecosystem in which young children engage routinely with science and math (e.g., Hurst et al., 2019). Home-based parent involvement in learning refers to parent-child activities that occur outside of school time (OST) and promote cognitive development. Decades of empirical evidence shows that broad parental involvement influences children's literacy and math achievement with small to moderate effects (Castro et al., 2015; Degol et al., 2017; Ma et al., 2016). Parent involvement in everyday activities that include STEM - such as cooking, grocery shopping, outdoor play, and games can promote young children's science and math knowledge (e.g., McClure et al., 2017; Nelson et al., 2016). The TT events were designed increase home-based parent STEM involvement by 
modeling how to "do science and math" during everyday routines. The events also sought to increase museum visits by giving free family admission passes to a local children's museum. Museums uniquely spark early STEM interest (e.g., Haden, 2010; Acosta et al., 2021).

There is evidence that families experiencing poverty may benefit from access to these types of educational resources to integrate science and math into family routines (Sonnenschein \& Sun, 2017; Starkey \& Klein, 2000). Schools can offer relatively low cost family education events to improve parents' knowledge, attitudes, and beliefs about children's learning (Caspe et al., 2018; Grindal et al., 2016). TT events are offered at schools and facilitated by museum-based STEM experts; events include encouraging parents to make small decisions to repeatedly weave STEM into home-based activities. Without these types of educative supports, parents often provide limited STEM learning supports (e.g., Bjorklund et al., 2004; Leyva et al., 2017). Further, caregivers may not recognize how STEM activities can develop higher-level reasoning skills and academic vocabulary (e.g., Conezio \& French, 2002; Gelman \& Brenneman, 2004; Greenfield et al., 2009).

Although home-based parent involvement is consistently linked to children's academic outcomes, school-based parent involvement (e.g., attending school events, volunteering in the classroom, fundraiser participation) has little relation with child outcomes (for review see Robinson \& Harris, 2014). Therefore, experts have called for a revised approach to schoolsponsored family engagement efforts that deemphasizes parent involvement in school events to focus on extending learning at home (Sabol et al., 2018). A focus on home-based parent involvement can improve equity, as families experiencing poverty may not have time or work schedules that allow parents to attend school events. Therefore, the TT program used text messages with linked activities and videos to ensure access to information on how to promote 
STEM at home. Text messages are a low cost nudge with actionable information and tips for parents to support learning with a series of small decisions to weave talk about math and science into day-to-day activities (e.g., Caspe et al., 2018; Cabell et al., 2019; York et al., 2019). Texts can prompt parent involvement in STEM and use of scientific vocabulary, with messages such as: "When doing daily routines (dishes, bathing, etc.) time yourself and say to [child's name] 'Let's see how long it takes us.' because this is collecting data." Texts can also include demonstration videos because modeling is a useful behavior change technique (Atkins et al., 2017). However, parents may experience other barriers that impede their involvement in their child's STEM learning. This study explored two additional conditions that could remove barriers to parent involvement for low-income families.

\section{Conditions that Support Families in "Doing Science and Math"}

We used behavior change and implementation science approaches (Atkins et al., 2017) to design three experimental treatment conditions that explored combinations of supports that increase parent involvement in STEM. Core TT components were provided to all treatment groups and included the aforementioned family STEM events, museum passes, and text messages. We then layered in two additional behavior change techniques (BCT) or mechanisms for changing the target behavior of parent involvement in STEM. Specifically, we added materials to a second treatment group (i.e., bilingual take-home STEM activity kits). We added the materials plus monetary rewards to a third treatment to reinforce parent involvement. This resulted in three randomly assigned treatments and a business-as-usual control group. (This theory of change/design is illustrated in Online Supplemental Figure A1 to show how targeted adult behaviors theoretically improve child outcomes, which were unmeasured due to COVID). 
The core treatment and additional BCT address three domains: (1) Parent capabilities (e.g., knowledge and skills) to facilitate home-based informal STEM activities with their preschooler as well as decisions to do informal STEM learning (e.g., remembering with text messages prompts). (2) Parent-child opportunities to do STEM at afterschool family events as well as resources to extend learning at home and at a children's museum. The additive treatment groups with take-home STEM kits further supported home-based STEM opportunities. (3) Parent motivation including beliefs about their perceived capabilities and expected outcomes of doing informal STEM. The additive treatment with parent rewards aimed to further increase the probability of parents facilitating informal STEM activities. Each treatment's components are listed in Table 1 and rationales for added materials and rewards are outlined in the next sections.

\section{Add Materials to Reduce Barriers}

Family STEM kits subscriptions are a popular trend that aim to support STEM inquiry at home by providing materials and step-by-step instructions (Reinhart et al., 2016). Commerciallyavailable kits have potential for exposing young children to STEM, but many kits are: (a) too costly for low-SES families, (b) contain complex instructions that require high English reading proficiency, and (c) require high levels of parent assistance (Brady, 2021). This study offered a second treatment with take-home STEM kits because families experiencing poverty may have limited access to STEM-related materials important to facilitate informal learning (e.g., Neuman, 2017). Activities designed specifically for informal learning at home may be important to promote STEM learning. For example, an effective STEM program called NURTURES has both formal and informal learning components; the informal learning includes family activity kits to support STEM inquiry at home (Kaderavek et al., 2020). Several effective pre-k classroom mathematics programs include aligned family materials (e.g., Clements \& Sarama, 2008; Starkey 
$\&$ Klein, 2000). Other approaches include informational texts because these materials build knowledge and create interactive discourse around STEM (e.g., Romance \& Vitale, 2012; Kim et al., 2019).

We used an additive design of layering take-home STEM kits onto the core treatment (rather than standalone kits) because it is established that simply giving families learning materials without additional training has little benefit (e.g., Neuman, 2017). Our take-home STEM activity kits included step-by-step photos, bilingual instructions, and parent tips (nine kits total $\$ 155$ per family). In curating our STEM kits, we observed families using a large number of possible kit activities and retained ones that: (a) produced high parent-child engagement; (b) were highly rated by parents, and (c) included inquiry- or play-based designs (rather than rote memorization). For example, this included structured sink/float activities (like Leuchter et al., 2014) and block sets with flexible attributes such as wheels and axles (like Ness \& Farenga, 2016). Few studies have considered the added benefit of take-home STEM kits on parent involvement.

\section{Add Rewards to Motivate Parents}

It is possible that some parents require more than just materials and information to overcome negative cultural stereotypes or previous negative experiences with science or math (McClure et al., 2017). Therefore, a third treatment in this study added parent rewards of $\$ 2.50$ per STEM activity. Perceived barriers to parent STEM involvement may include diverse aspects of motivation. For example, many adults report low beliefs about capabilities for "doing science" in developmentally appropriate ways (Greenfield et al., 2009). Some adults might expect math and science activities to be unpleasant (Jameson \& Fusco, 2014). We hypothesized that giving 
parents monetary rewards could demonstrate that STEM is valuable and offset perceived costs (e.g., high effort demands, loss of time for alternative activities).

Yet it is unclear whether using extrinsic, monetary rewards could effectively promote parent STEM involvement. A recent study that rewarded parents $\$ .50$ for completing shared book reading sessions with their preschooler, found this was the most effective BCT amongst various techniques tested in a home literacy treatment (Justice et al. 2018). Although this was a relatively modest reward (up to $\$ 37.50$ across $\sim 15$ weeks and 60 sessions), Justice and colleagues (2018) attributed the success of rewards to incentivizing parents to overcome time pressures to engage in this learning activity they already hoped and intended to do with their child. Yet, family engagement in STEM requires investments in less discrete activities as well as habits of inquiry and exploration (McClure et al., 2017); thus, it is unclear whether rewards of $\$ 2.50$ per STEM activity are well aligned with goals of sparking family STEM interest. STEM inquiry is considered intrinsically rewarding (NRC, 2009). Although extrinsic rewards can undermine intrinsic motivation in children (Deci et al., 1999), for adults extrinsic rewards can boost performance and compensate for time pressures or other aspects of low motivation (e.g., Parker et al., 2017). Thus, rewards warrant empirical study as a relatively low cost way to increase parent involvement in STEM.

\section{Past \& Current TT Studies}

Museum educators who were working with recent Spanish-speaking immigrants initially developed the family events model used in this study (i.e., program titled Para Los Niños; Author, 2007). A recent TT Language/Literacy study suggested promise of the family events with text messages for increasing vocabulary (Author et al., 2021a). In the 2018-19 school year, museum educators and researchers extended and field tested the TT STEM program and new 
take-home materials at four schools. This included parent feedback from diverse families, including a majority of Black and Hispanic/Latino populations that are historically underrepresented in STEM (Bruyere et al., 2009), resulting in the components in Table 1.

The present study evaluated the impact of TT STEM treatments on the frequency of parent involvement in STEM activities with their child. To broaden access to early STEM opportunities, we recruited a sample of schools where the majority of students were experiencing poverty; these schools also served mostly Black and Hispanic students. We answered two research questions: (1) Which conditions are most effective for increasing parental involvement in informal STEM learning? (2) To what extent do parents uptake the TT STEM program components and find them satisfying and feasible to use? We hypothesized that parents in all TT conditions would report greater involvement in STEM activities after any treatment exposure because of the core BCT of increasing parent knowledge, skills, and social supports to do STEM with their child. We also contrasted the relative efficacy of the core treatment to the enhanced treatments. We hypothesized that parents who received the take-home kits would report more frequent STEM because this BCT changed the environment in ways that could reduce barriers to gathering STEM resources or improve parents' beliefs that they could successfully do STEM with a prepared activity. Finally, we expected the BCT of contingent monetary rewards would further boost parent involvement because it reinforced the value of doing STEM. For the second question, we considered the extent to which parents participated in offered workshops and used quantitative and qualitative survey responses to understand barriers to parent involvement in STEM. We expected the primary barriers to parent involvement to include limited time, but we hypothesized that we could reduce barriers to accessing materials in the conditions where kits were provided. 


\section{Method}

This study occurred in the 2019-20 school year in a metropolitan area in the southwestern region of the U.S. We used a cluster randomized control trial (RCT) design that recruited families with pre-k children from three public school districts. The family events in treatment schools were conducted by Children's Museum [Name Removed]. The study was interrupted by the COVID pandemic in March 2020; details of protocol changes are provided below.

\section{Child and Family Participants}

Table 2 shows demographics. Across the 181 children who were randomized into the study, the mean age of students was 4 years and 5 months $(S D=0.34$ months; range 3 years 5 months to 5 years); about $51 \%$ were female. Parents completed demographic questionnaires (5 missing); most were completed by mothers ( $n=152,83.98 \%$; fathers $n=13,7.18 \%$; grandparents/other caregivers $n=9,4.97 \%$ ). For race, $50 \%$ of children were Black/African American $(n=91), 23.30 \%$ were White $(n=41), 6.25 \%$ were Asian $(n=11), 11.93 \%$ selected other race $(n=21)$, and $6.82 \%(n=12)$ no response. For ethnicity, $35 \%$ of children were Hispanic/Latino/a $(n=62)$. About $50 \%$ of parents spoke a language other than English at home $(n=88)$, with $63 \%$ speaking Spanish followed by Other languages $(16.48 \%)$, an African language (9.89\%), Arabic (4.40\%), and Vietnamese (3.30\%). The child's language most spoken at home, 90\% $(n=157)$ was English. Median yearly household income from parents was $\$ 20,001-\$ 30,000$ (missing for 28 families); this is consistent with the 2019 federal poverty threshold ( $\$ 25,750 /$ family of four). Median mother education was some college (missing $n=6)$ while fathers' was high school diploma/GED (missing $n=12$ ). About $34 \%$ of mothers and $43 \%$ of fathers had a STEM-related career (missing $n=13$ ).

\section{Procedures}


We conducted research in 20 schools across three districts. Eligible schools had to serve a majority of low-income students; $92 \%$ of students at these schools were eligible for free/reducedprice meals $(\min =52.2 \%, \max =100)$. We worked in 46 pre-k classrooms. Principals requested minimal study activities for teachers; therefore, teachers helped share recruitment flyers with families and were encouraged to attend the afterschool workshops (if assigned to treatments), but this was optional. Families within schools were recruited via several methods including meetthe-teacher and back-to-school family events, flyers in school-home folders, and parent conversations at drop-off/pick-up times.

We invited all pre-k families within treatment classrooms to attend TT workshops; a subset of parent-child dyads - the focal sample - participated in research activities after providing written parent consent (HSC-MS-15-0759). Focal dyads were eligible if: (a) the child was 3.5- to 5-years-old by 9/1/19, and (b) the family spoke a primary language of English or Spanish because the program was only available in these languages. When $>6$ families consented per classroom, we randomly sampled four to six dyads $(M=3.89$ dyads per classroom; $S D=2.32$; $\min =1, \max =9)$

\section{Data Collection}

All examiners were trained $100 \%$ adherence on data collection procedures using a mock child test administration and practice in the field. Families could select parent-child data collection at school or home; most selected school. All focal families received a $\$ 50$ gift card after baseline and $\$ 50$ after posttest. The posttest battery was shortened due to COVID (i.e., no child level data). To cover cellular data costs associated with text messages, families received a \$40 gift card. Testing occurred September-November 2019 for baseline, May-July 2020 for pre-k posttest and January-March 2021 for kindergarten (K) follow-up. Due to scheduling challenges, 
baseline did not represent a true pretest for 21 families (15\% of 137 in treatment groups) because family intervention had started; these families were dropped from main impact analyses.

\section{Randomization \& Attrition}

We randomly assigned schools to the treatment or control, blocking on two variables school district and proportion of EL students $>50 \%$. We documented parent-child dyads attrition using CONSORT flowchart in Online Supplemental Figure A2. The overall attrition rate was $22.65 \%$ with acceptable levels of differential attrition for Treatments B and C, but attrition outside acceptable levels for Treatment A. These data are detailed in Online Tables A1-A2.

\section{Group Descriptions}

\section{Control Group}

Families in the control group experienced their school's business-as-usual (BAU) family engagement offerings, which most parents rated as good at baseline $(M=5.93, S D=1.66$ scale 1 - not true at all to 7 - very true; sample item: "My child's school provided activities for parents and children to do math/science at home.”). Control group families received an equivalent number of 24 text messages as treatment families, but on non-STEM topics (e.g., safety, health, letter recognition). Texts were personalized with the child's first name, such as: "Sleep Habits [child first name] needs 10-12 hours of sleep each night. Sleep can affect [child first name]'s growth and behavior." Parents reported high satisfaction with developmental text messages.

\section{Treatment A: Core Program}

The core treatment included family workshops, access to a children's museum, and STEM text messages. All families in participating classrooms were invited to six afterschool workshops within their child's school library or cafeteria on the topics outlined in Table 1. Museum educators facilitated workshops with most occurring between 3:00pm to 5:30pm. 
Workshops began with attendance tracking, pizza, a 2-minute video on parent-child STEM interactions, and a handout on the focal STEM strategies and suggestions of how to explore this topic in the local museum gallery. Then, the facilitator modeled the focal strategy with interactive book reading. Finally, the facilitator explained four to six STEM activity stations $\backslash$ for families to practice the strategies. See Supplemental Appendix Table A3 for photos. As the event concluded, families received a Children's Museum [name removed] family pass (value \$72) and completed a satisfaction survey.

Importantly, the museum facilitator interacted with each family providing support, specific praise for strategies observed, and suggestions to guide children's learning. The museum facilitators were Hispanic bilingual (English/Spanish) females with 10 years and 18 years of family engagement experience, respectively. All written materials were bilingual. At schools with large numbers of Spanish-speaking families, the events were presented bilingually.

Parents also received automated text messages. One week prior to workshops and again two days before, parents received event reminder texts (time and location; see samples in Supplemental Table A4). Parents received 24 informational texts with tips and activity suggestions aimed at increasing parent involvement in informal STEM learning (see Table A5). Texts sent the day after the workshop explained focal strategies, such as: "Counting and recognizing numbers are some of the first early math skills children need to learn. Encourage your child to count items during everyday routines! For example, when cleaning up ask your child to pick up a set number of objects and count with [him_her].” Four days later, we sent another informational text with a modeling video. For example, "The more opportunities children have to count the easier it will become. Follow this link for a fun counting activity: 
[www.blindforreview.org]" Additional texts were sent eight and 12 days after workshops (see Supplemental Table A4). Messages were in English or Spanish, according to parent's preference. Treatment B: Add STEM Kits

This condition increased access to STEM materials by providing take-home STEM kits. Although the workshops/text messages emphasized that science and math can be done anywhere with common household objects (e.g., math in kitchen, observing natural environment), these nine kits included STEM-related books and activities with step-by-step photos and bilingual instructions (see Table 1). The added STEM kits cost $\$ 155$. These parents received nine extra text message reminders to use kits related to recent workshop topics: "Use the Family Kit 2 'Sink or Float?' Designing, building and testing a boat to accomplish a task is engineering design.”

\section{Treatment C: Add Rewards}

This condition added parent monetary rewards to the aforementioned core components and kits to incentivize parent involvement. Rewards of $\$ 2.50$ were contingent on sending researchers a photo or text message response. At six times, these parents received text message reward reminders: "Tell us about an activity you did with [child name] this week to support [his/her] learning. Include a photo if you like. If you reply, you will get $\$ 2.50$ added to your card." A maximum of $\$ 40$ on reloadable debit cards was given.

Adjustments \& COVID Changes. During the treatment period, we made minor adjustments to study marketing to improve attendance. Although $80 \%$ of schools $(\mathrm{n}=12)$ were able to host the recommended four to six workshops, due to COVID-related school closures, other schools offered fewer workshops. No museum field trips were offered due to COVID; see Online Table A6-A7 for details.

\section{Cost Analysis}


We used the ingredients method (Levin et al., 2018) to capture treatment costs per school and per student/family. This includes three cost categories: (a) personnel (e.g., museum educator training and facilitation time); (b) materials and equipment (e.g., workshop materials, family kits); and (c) other miscellaneous costs (e.g., personalized text messaging service). The detailed cost analysis is in Online Supplemental Table A8. The core Treatment A was approximately $\$ 84$ per student for one workshop or $\$ 300$ per student for all six workshops. The Treatment B kits added \$155 per student. We do not expect schools to implement the experimental reward condition; however, this added up to $\$ 40$ per family. These values reflect actual, local costs.

\section{Measures}

\section{Parent Surveys}

Parent Involvement. The primary outcome measure was home-based parent involvement collected with a questionnaire at baseline, pre-k posttest, and $\mathrm{K}$ follow-up. We measured parent involvement in STEM learning with 10 items that asked about the frequency of STEM-related activities. Responses to these items ranged from 1 to 4 (1-Not at all; 2-Once or twice a week; 3-Three or more times a week, but not everyday; 4-Everyday). Sample items include: "How many times in the past week have you compared sizes of objects or toys with your child?" "How many times in the past week have you talked to your child about plants, animals or other living things?" These items were adapted from the Head Start Family and Child Experiences Survey (FACES; West et al., 2009). For comparison, we interspersed some literacy items; for example, "How many times in the past week have you read books to your child?" We created additional STEM items (e.g., weather/seasons, plant and animals) beyond the FACES items, using the same item structure. Sample reliability was Cronbach's alpha $=0.85$. Table 3 shows descriptives for parent involvement items. 
Parent Satisfaction \& Feasibility. Parents completed satisfaction surveys at the end of each workshop (i.e., all attending parents, including focal families and others from participating classrooms). This included usefulness ratings of all workshop components (videos, shared reading, activity stations, handouts; Likert scale 1-Not Useful, 4-Very Useful). Second, we asked questions at posttest about how useful families found each TT STEM components.

We asked parents quantitative and qualitative feasibility questions at baseline and posttest about feasibility of informal STEM. Quantitative items used a Likert scale (1-Not true at all, 7-Very true) to measure perceived barriers associated with parent involvement (e.g., "Because of the other things that I have to do, I don't have enough time to do science with my child."). Reliability for this sample is alpha $=0.84$. We also asked open-ended questions for qualitative analysis. For example, treatment family questions included: "How do you plan to support your child's learning?" or "What do you think are the top barriers to... families doing science and math activities; attending attend afterschool events; etc."

\section{Parent Uptake Measures}

A measure of treatment dosage was family attendance at TT STEM events, based on sign-in sheets at workshops. Another measure was parent responsiveness to text message requests from researchers to all groups: "Tell us about an activity you did with [child first name] this week to support [his/her] learning. Include a photo if you like.” We coded all photos/videos for the type of activity using materials and setting to assign categories of math, science, engineering, literacy, or other.

\section{Fidelity of Implementation}

To ensure ISE facilitator adherence, two museum supervisors observed workshop implementation at nine workshops across different treatment schools. Items across four domains 
were scored on as yes $=1$, no $=0$ to calculate the proportion of steps implemented following the protocol. There was high fidelity observed for all domains measured: (1) $94 \%(S D=0.098)$ introduction steps delivered (e.g., "Clearly and concisely restates strategy."), (2) 97\% (SD= 0.076) shared book reading steps (e.g., “Asks questions which support children’s understanding of book.”), (3) 100\% of activity stations (e.g., "The activity was explained fully by facilitator.”), and (4) 100\% general management throughout the workshop (e.g., "Redirects disruptive behavior positively.").

\section{Data Analysis Plan}

To examine the main impact of the treatments on parents' STEM-involvement at the endof-treatment and K follow-up, we first estimated the intent-to-treat (ITT) using ordinary least squares regressions (OLS) correcting for the clustering by using robust standard errors at the classroom and school-level. The number of families with a parent survey at end-of-treatment (i.e., non-attriters) was 140. From these non-attriter families, $17(12.14 \%)$ completed their baseline survey after attending their first STEM event and were excluded from the analytic sample. Thus, the analysis is based on 123 parent-child dyads. For the ITT, we estimated the following three models. Model 1 regressed the outcome on the baseline and the three treatments (control was used as a reference category). Model 2 added family-level demographic characteristics: child's sex were male $=0$ and female $=1$; whether a language other than English is spoken at home where $0=$ no, $1=$ yes; parent education where we used the highest level of education of the mother or father; the number of parents that had a STEM-related career where 0 $=$ none, $1=$ one parent, 2 = two parents; race/ethnicity of parent were three dummy variables were used for White, Black, and Hispanic. For Model 3, we added school-level variables looking at percent of economically disadvantaged students, percent of students with a Limited English 
Proficiency status, and percent of students with special education. The school-level variables were retrieved from the LEA [blinded] reports for 2019-20 school year. We also report the treatment of the treated (TOT) estimates by dividing the ITT estimates by the percent of treatment group members who were treated. This adjustment approach is appropriate given that there were no cross-overs in our experiment (only no-shows). For the TOT, we define treatment as attending at least one STEM event. This was $40 \%$ for Treatment A, $65 \%$ for Treatment B, and $56 \%$ for Treatment C. We had minimum levels of missing data on family-level covariates included in models 1 and 2. To keep our sample size consistent across all model specifications, we relied on a dummy imputation approach which is a missing data method recommended by What Works Clearinghouse Standards (What Works Clearinghouse Standards, 2021). Specifically, we replaced missing data with a constant combined with the inclusion of a missing data indicator. Note that as part of the sensitivity analysis checks, we re-estimated analysis using a multiple imputation approach.

Unfortunately, this sample ( $n=20$ schools and 181 students) was not adequately powered to detect our expected small effect sizes. Considering the current sample's (a) ICC of the parent involvement outcome (8\%), (b) where the observed variance explained of the baseline parent involvement is $40 \%$ and level-2 predictors explain $25 \%$ of variance, and (c) where the harmonic mean of families per school is 5.41, a post-hoc power analysis suggested statistical power at $80 \%$ to detect a minimum detectable effect size (MDES) of 0.62. Since we do not have adequate statistical power within this cluster RCT, we retained an alpha threshold of 0.05 but considered $p$ values of 0.10 as potentially meaningful.

To examine the second question around parent uptake of the treatment components and perceived barriers to informal learning, we report descriptive statistics and themes from 
qualitative analysis of parents' open-ended survey responses. When surveys were completed in an interview format, we transcribed parents' responses verbatim. The lead author and a research assistant applied codes that were derived from an implementation science framework (i.e., Atkins et al., 2017) as well as etic codes specific to the STEM content. We calculated inter-rater agreement on coded qualitative areas and confirmed the conclusions drawn from these data; coding agreement was $97.8 \%$ and coders reached consensus on qualitative findings.

\section{Results}

\section{What is the impact of the three additive treatments on parent STEM involvement? End of Pre-k Treatment Posttest}

Table 4 presents the results of the three model specifications described above for the ITT and TOT. There were no statistically significant associations found regardless of model specification, thus we interpret models based on their effect size. For model 1 (only controlling for baseline) we found that compared to the control condition, all of our treatment conditions had lower levels of parent involvement, with ES for the TOT ranging from -0.61 to -0.46 . When adjusting for family-level variables, effect sizes ranged from -0.46 to -.20 . Model 3, which adjusts for both family and school characteristics before comparing treatments to control, we found that Treatment A (core program) had lower levels of parental involvement $(\mathrm{ES}$ for TOT = -0.01) and Treatment B (core program + kit) had no meaningful differences in levels of parental involvement $(\mathrm{ES}$ for TOT $=-0.08)$. In this specification, Treatment $\mathrm{C}$ (core program + added kit + rewards), had higher levels of parent involvement when compared to the control group (ES for TOT $=0.18)$.

When comparing among the three treatments (see Table 5), we found that across all three specifications, Treatment $\mathrm{C}$ had either higher or approximately equal levels of parental 
involvement than Treatment A (ES for TOT ranging from -0.05 to 0.19 , depending on the model specification) and higher levels of parental involvement than Treatment B (ES for TOT ranging from 0.25 to 0.33 , depending on the model specification). However, Treatment B had lower levels of parental involvement compared to Treatment A ( $E S$ for TOT ranging from -0.26 to .08). None of these differences were statistically significant.

\section{Follow-up in Kindergarten}

As shown in the middle panel of Table 4, patterns for the follow-up outcomes were similar to posttest for model 1 and model 2, where all three treatments had lower or no different levels of parental involvement when compared to the control group. For model 3, which adjusted for family and school-level characteristics, Treatment A had lower levels than control (ES for TOT is -0.94), Treatment B had higher levels than the control condition (ES for TOT is 0.34), and Treatment $\mathrm{C}$ had similar levels than control (ES for TOT is -0.01). Again, none of the differences were statistically significant.

When comparing the three treatments (see Table 5), we found that across all three specifications, Treatments B and C had higher levels of parental involvement when compared to Treatment A (ES for TOT ranging from 0.11 to 1.05 for Treatment B, and to 0.21 to 0.63 for Treatment C). When compared to Treatment B, the direction of the difference on parental involvement when compared to Treatment $\mathrm{C}$ was not clear, where models 1 and 2 suggested higher levels of parental involvement for Treatment C (ES ranging from 0.12 to 0.17 ) and model 3 suggested lower levels for Treatment $\mathrm{C}$ when compared to Treatment $\mathrm{B}(\mathrm{ES}=-0.31)$. None of these differences were statistically significant.

To what extent do parents uptake TT components and find them satisfying and feasible? Workshop \& Text Message Uptake 
We measured focal family attendance at TT STEM events. Across all groups, we had rather low attendance rates $(M=1.5$ events, $S D=1.7)$. The pattern of attendance, shown in Online Supplemental Figure A3, shows parent attendance improved at workshops 2 through 4 but, at workshops 5 and 6 attendance was lower. Attendance for focal families ranged from 16\% to $36 \%$. Descriptively, we looked at which families were most likely to attend the workshops. To this end, we categorized attendance into five groups: (a) Group 0 had those families who attended no STEM events $(n=60)$; (b) Group 1 had families who attended $<=25 \%(n=22)$; (c) Group 2 was families attending between $>25 \%$ and $<=50 \%(n=24)$; (d) Group 3 had families attending $>50 \%$ and $<=75 \%(n=16)$; (e) Group 4 had those families who attended $>75 \%$ of STEM events $(n=15)$. Table 6 reports on several descriptive characteristics by group. Families that attended $>50 \%$ of workshops (groups 3 and 4 ) had higher levels of mother's education and father's education, higher proportion of White parents, and higher incomes than those families who attended $<=50 \%$ of the workshops. We explored the statistical significance of these levels using the Kruskal-Wallis test (a non-parametric one-way ANOVA) and found that the only significant characteristic at $p<.05$ was father's education $(p=.034)$; there was a trend such that White parents had higher attendance levels $(p=.060)$.

We asked treatment parents to qualitatively describe barriers to attending the TT STEM events. The most salient theme was coded as Opportunity - limited time. This was exemplified by responses such as, "I work and attend school so I was tired some days. And my son also attends swimming and gymnastics during the week." Seventeen parent responses indicated limited time due to conflicting work schedules (or parent enrollment in courses/education) and 12 indicated limited time due to conflicting family commitments (e.g., sports and afterschool activities). 
Despite these barriers, one Treatment B parent noted: "I went to all of them [workshops]...I asked to leave early from work so that my child could see and feel my support."

Across all groups, parents were invited to send a text message to researchers with a written response and/or photo indicating how families supported their child's learning that week. About a third of families $(34.81 \%, n=63)$ sent one or more written/photo responses across all condition groups. The majority were coded as math type activities across all conditions (36.18.02\% math, $17.57 \%$ science, $12.08 . \%$ engineering, $18.54 \%$ literacy, and $15.62 \%$ other), but there was a pattern of more science activities in the treatment groups $(24.66 \%)$ compared to the control group (6.05\%). About $21(47.73 \%)$ parents in Treatment $\mathrm{C}$ - with rewards contingent upon text response - sent at least one photo/video or text response, compared to seven parents (19.44\%) in Treatment A, $23(40.353 \%)$ in Treatment B, and $12(27.27 \%)$ in the control group.

\section{TT STEM Satisfaction}

TT Workshops. Across 341 total workshop exit surveys (including focal parents and other families in participating classrooms), the majority of parents $(83.6 \%)$ praised the workshops giving the highest rating ( $n=285$ unique respondents). For the focal families, their TT STEM workshop ratings indicated high usefulness on a 4-point rating: $M=3.84(S D=0.47)$. For example, parents reported, "We really enjoyed the workshop. We learned activities to use with simple items around the home." or "Everything was nice and educational. [Name of the museum educator] storytelling is awesome!" There were few focal family suggestions for improvement with the exception of one request for later workshop times for working parents and, at some schools, more activity stations/space because there were large numbers of families attending.

Other TT Components. Ratings were good for the usefulness of text message tips/prompts $(M=3.16, S D=1.01)$ and activity links $(M=3.36, S D=0.85)$. Regarding the 
family museum passes, most families reported visiting the museum during the school year $(n=$ $50,54 \%$ ); there were $24 \%$ of families who had not attended but planned to visit soon (e.g., when the museum gallery reopened after COVID-related closures). For Treatment B and C, parents reported high satisfaction with the take-home kits $(M=3.92, S D=0.27)$. They reported using most kits 1 to 4 times; the most frequently used activities included blocks for building vehicles, a counting and sorting book with manipulatives, and an ocean-themed puzzle and book. We also asked families if their use of treatment components increased, decreased, or stayed the same after COVID and the general pattern showed their usage stayed about the same. For Treatment C only, parents reported that receiving the reward text message (earn $\$ 2.50$ for sending a photo or explanation) was somewhat helpful $(M=2.95, S D=1.10)$.

\section{Feasibility of Home-based Parent Involvement in STEM}

In the quantitative survey items that asked parents to rate barriers to doing informal STEM learning such as time, effort, and access to materials, parents did not mark any items as salient barriers (averages range from 1.89 to 2.56) on a 7-point scale where higher values are salient barriers and the mean of 2.39 indicates "mostly not a barrier." Item-level descriptives are at Online Appendix Table A9. For example, the highest baseline barrier was "materials to do science." At posttest, the highest ranked barriers were, again, science materials and time to do science and math.

At posttest, we coded treatment parents' qualitative responses $(n=50)$ to questions STEM involvement and barriers. We asked parents how they intended to support their child's learning indicated that they planned to use many of the target STEM strategies including: counting (60 responses), building with blocks or household materials (36 responses), asking questions (26 responses), gathering data (18 responses), predicting (16 responses), discussing 
sophisticated or science words (17 responses), and identifying patterns (13 responses). The most salient theme was that parents were counting more with their child. One parent said "Counting while playing - simple, and easy to implement" and another said they could "turn everything into counting." Other parents internalized engineering concepts with statements such as, "We are going to try designing a solution to a problem at our house by fixing a broken object." Many parents planned to ask more inquiry questions; one parent said 'I will focus on asking 'Why?' questions more."

Turning to qualitative data on barriers, across treatment groups ( $\mathrm{n}=66$ responses), the most common barrier reported was coded Opportunity with two subcategories. The first, Opportunity - limited time was represented by $34 \%$ of parents' responses. One parent explained, "Full time job, multiple kids, at home responsibilities with everyday life and homework and now more with online school it is very difficult to help them all." The second type was Opportunities - limited resources reported by $28 \%$ of parents. For example, a parent said, "there is not enough material to use and manipulate.” Importantly, fewer parents in Treatments B and C, which received STEM kits, reported access to STEM resources as a barrier. Specifically, $67 \%$ of parents in Treatment A qualitative responses included material resources as a top barrier, compared to $10 \%$ and $25 \%$ of parents in Treatment B and C, respectively. Yet the program messages and strategies emphasized that you can do STEM without access to special learning materials. A parent in Treatment B internalized this and said, "They think they need actual kits but I have learned that you can use any regular household item to create a science experiment. In all actuality at times you don't even need anything to create a scenario related to science."

Amongst the remaining barriers, the next theme reported by $22 \%$ of parents was Capability in terms of parent knowledge to support science and math learning at home. This was 
illustrated by comments that it was difficult to "really know what they should know by a certain age." A few parents noted they needed "some patience" or capability to "listen closely" to their child. A final barrier was Motivation that was note by $20 \%$ of parents. This was related to competing interests for their children's attention, as illustrated by this response: "lack of interest from the children makes it easier for us to give them a tablet or phone so that they can watch other types of programs."

\section{Discussion}

This study explored conditions that are most likely to increase parent involvement in STEM with their young child. We randomly assigned schools to a control condition or one of three additive treatment groups with STEM workshops and parent text messages as the core components. We added take-home activity kits and parent rewards in the other treatments. There were no significant impacts in any treatment group on the primary outcome of home-based parent involvement in STEM; however, there were promising effect sizes of the more intensive treatments that included materials to scaffold STEM learning at home. Monetary rewards for parents showed promise for short-term outcomes but benefits faded over time. We discuss these findings as well as which treatment components were most feasible for parents to uptake, as these descriptive findings have implications for broader family engagement approaches.

\section{Conditions that Best Supported Early Parent Involvement in STEM}

Parent involvement warrants study because it is consistently linked to children's academic achievement (Castro et al., 2015; Ma et al., 2016). Although we found no significant effects of the TT STEM program on parent involvement at pre-k or K follow-up, we consider why the effect sizes were larger for the more intensive treatments that provided take-home family kits. Interestingly, the added rewards Treatment $\mathrm{C}$ improved immediate parent 
involvement in pre-k $(\mathrm{ES}=0.18)$, but these benefits faded over time such that at $\mathrm{K}$ follow-up only Treatment B with take-home kits showed sustained improvement in parent behaviors $(\mathrm{ES}=$ 0.34), relative to the control group. When comparing within treatments, there were minimal differences at end of pre-k, but by $\mathrm{K}$ follow-up the conditions with added materials were superior to workshops alone, with larger and practically meaningful effect sizes $(\mathrm{ES}=0.63$ to 1.05$)$. A potential reason for the promise of adding materials within the qualitative data was that adding materials reduced barriers to "doing science and math" at home. Indeed, only $25 \%$ or less of parents in the treatment groups with take-home kits reported materials was a barrier to informal STEM learning, compared to $67 \%$ of parents in core treatment.

Provision of STEM learning materials to families experiencing poverty warrants future consideration given inequities that were exacerbated by the COVID pandemic (Caniglia et al., 2021). We suspect that providing materials alone, without education events and resources, will be ineffective (e.g., Neuman, 2017). Yet the lack of significant differences may be due to the limited scope of these kits. In other words, it is unlikely that one year of pre-k education events and take-home activities provides sufficient, long-term experiences for families to develop broad and deep interest in informal STEM (NRC, 2009). Indeed, effective STEM approaches combine parent education with take-home activities over several grade levels (Kaderavek et al., 2020) or with multiple museum visits that provide unique settings for developing broad STEM interests (Pattison et al., 2020). Future studies should tease apart intensity issues as well as the extent to which step-by-step kits versus more open-ended materials for exploration and tinkering are beneficial (e.g., Acosta et al., 2021).

Potential explanations for the short-term benefit of the added rewards condition are that in this sample of families who were experiencing poverty and often had full-time jobs - 
monetary rewards may have urged parents to overcome time pressures or other constraints to informal STEM learning. Although we cannot recommend this BCT without further evaluation, it may be that modest rewards incentivize parents to engage in STEM activities they already hoped and intended to do with their child (e.g., Parker et al., 2017). Indeed, monetary rewards are a BCT designed to offset immediate perceived costs (Atkins et al., 2017), such as the effort to engage in an inquiry-based activity, which takes time away from other parent activities (e.g., work responsibilities, household tasks, leisure time). It may not be surprising that benefits of these rewards faded when they were withdrawn at the $\mathrm{K}$ follow-up survey. Our findings that rewards may offer temporary support are similar to a recent pre-k shared book reading study found the most effective short-term BCT for encouraging parents to read with their child was paying parents $\$ .50$ for each book reading session (Justice et al. 2018). Adding these $\$ 2.50$ rewards for doing a STEM activity may have helped to overcome parents' anxieties about math or science, negative cultural stereotypes about STEM, or other limiting beliefs about how to effectively engage children with science and math (e.g., Greenfield et al., 2009; Jameson \& Fusco, 2014; McClure et al., 2017).

A final explanation for the lack of significant differences for treatments vs. control is that the text messages within the control group may have unintentionally improved parent involvement. We used some of these control text messages in a prior study and found that, for some families, this type of developmental information (e.g., healthy sleep habits, nutrition tips) was more beneficial to children's learning than a different set of treatment text messages focused on language and literacy outcomes (Author et al., 2019). Perhaps future TT STEM studies should use an untreated control group. Indeed, other research shows that texting developmental tips or parent strategies can improve child outcomes (e.g., York et al., 2019). 


\section{Feasibility and Redesigning to Address Barriers to Informal Learning}

Our findings suggest that there may be a threshold for the number of events parents can realistically attend afterschool. Although parents reported high satisfaction with the TT STEM events, they only attended an average of 1.5 of the six family workshop events. Qualitative data indicated that limited time was the major barrier to this type of family engagement; parents reported conflicting work schedules and family commitments. Based on the earlier study TT with language and literacy workshops (Author et al., 2021), we found a similar average attendance of $26 \%$ of events; we also used more frequent parent text reminders in this study indicating this is not merely a memory issue or that parents forget to attend. Our cost analysis found a cost of $\$ 85$ per student for each workshop, assuming 22 families per classroom attend. Obviously, the cost per student increases substantially if fewer families attend.

We found that across treatments, $50 \%$ to $71 \%$ of parents attended at least one of the six workshops. Our family event participation rates are similar to or better than other family engagement studies where families complete $35 \%$ to $75 \%$ of offered events/activities (e.g., Bierman et al., 2015; Justice et al., 2018; Kim et al., 2019). For example, a recent family program held a kickoff event to provide informational science texts and other books with a summer reading app for kindergarten through Grade 2 (Kim et al., 2019). About 35\% to $40 \%$ of parents attended this event, compared to $56 \%$ of parents who attended the first TT STEM event. In the Kim et al. study, if families did not access complete at least one reading activity in the program's app, they were considered non-responsive and in need of an adaptive, second stage of treatment, such as adding parent text messages or gamification to the app. Out of the 273 randomized families in Kim's study, only $26 \%(n=71)$ accessed the family app called MORE@HOME. We can compare their app engagement to our families' uptake of text 
messaging, which was a higher responses rate (e.g., send a photo of your child's learning) than what was reported by Kim and colleagues (35\% or 63 families out of those 181 randomized).

Descriptively we found significantly higher workshop attendance for families with higher maternal education levels. There was also one finding that parents who attended more workshops were also more engaged in texting pictures of informal learning. Thus, in future fully powered studies, we will consider if attending more STEM events improves informal learning (cf.

Reinhart et al., 2016) and potential moderators to understand for whom TT STEM events may be most beneficial. We will also redesign our intervention approach in key ways that include: (a) directly survey families on their preferred times for OST events (Beckett et al., 2009), rather than using times that a school coordinator says are convenient for families; and (b) working more systematically with teachers to engage families because this may improve attendance and educators' capacity to create genuine partnerships with families (Ma et al., 2016).

\section{Limitations \& Future Directions}

Given how this underpowered sample was impacted by COVID, this study cannot provide definitive answers about conditions that best support parent involvement in informal science and math. For example, treatment effects may have been altered at the pre-k posttest such that parents were more involved than usual due to COVID-related school closures; alternatively, parents may have been stressed by the pandemic and less involved in informal learning at the pre-k or K timepoint. In other words, the reliability of our parent involvement survey could be low given ongoing pandemic disruptions.

Future studies should consider other broader parent perspectives that include enthusiasm for STEM activities and observational measures of parents' implementation of the focal strategies during parent-child STEM interactions (cf. Acosta et al., 2021). It is possible that we 
did not capture a full range of treatment effects in areas such as parent and child STEM interest, which are hypothesized to be important to long-term STEM career pathways (e.g., Pattison et al., 2020). In future research, we will measure these constructs and revise components of TT STEM to improve feasibility and parent uptake.

Another limitation is that there was differential attrition in the Treatment A group such that parents with lower education and income were more likely to leave the study. Although these families may been impacted by the pandemic, future studies should continue to monitor profiles of families who withdraw and seek to understand reasons families do not uptake aspects of the treatment. Likewise, another issue is the relatively low response rates on the kindergarten parent surveys, which limits inferences we can draw from these data.

\section{Conclusion}

Although we could not measure child outcomes and this study was impacted by COVID, the pattern of findings for parent outcomes aligns with meta-analyses that light touch educational events produce null to small impacts (Grindal et al., 2016). Yet the results demonstrate that families experiencing poverty can be better supported to engage in early STEM activities with their young children under certain conditions. That is, giving families access to both educational resources alongside materials that scaffold informal learning were the most beneficial treatments for improving parent involvement in this sample. This aligns with recommendations to promote informal STEM learning in ways that ensure access to parents with complex job and caregiving situations (Hurst et al., 2019), as take-home kits can make it more simple to use their limited time to promote STEM learning at home. Further research is needed to tease apart what combination of information, resources, materials, and rewards are optimal BCT to broaden access to informal STEM learning for families of young children experiencing poverty. 


\section{References}

Author 2007, 2019, 2021a, 2021b, Author, in review

Acosta, D. I., Polinsky, N. J., Haden, C. A., \& Uttal, D. H. (2021). Whether and how knowledge moderates linkages between parent-child conversations and children's reflections about tinkering in a children's museum. Journal of Cognition and Development, 22(2), 226245. https://doi.org/10.1080/15248372.2020.1871350

Atkins, L., Francis, J., Islam, R., O’Connor, D., Patey, A., Ivers, N., Foy, R., Duncan, E. M., Colquhoun, H., Grimshaw, J. M., Lawton, R., \& Michie, S. (2017). A guide to using the Theoretical Domains Framework of behaviour change to investigate implementation problems. Implementation Science: IS, 12(1), 77-77. https://doi.org/10.1186/s13012-017$\underline{0605-9}$

Beckett, M., Borman, G., Capizzano, J., Parsley, D., Ross, S., Schirm, A., \& Taylor, J. (2009). Structuring Out-of-School Time to Improve Academic Achievement. IES Practice Guide. NCEE 2009-012. What Works Clearinghouse.

Bierman, K. L., Welsh, J. A., Heinrichs, B. S., Nix, R. L., \& Mathis, E. T. (2015). Helping head start parents promote their children's kindergarten adjustment: The research- based developmentally informed parent program. Child Development, 86(6), 1877-1891. https://doi.org/10.1111/cdev.12448

Bjorklund, D. F., Hubertz, M. J., \& Reubens, A. C. (2004). Young children's arithmetic strategies in social context: How parents contribute to children's strategy development while playing games. International Journal of Behavioral Development, 28(4), 347-357. https://doi.org/10.1080/01650250444000027

Brady, A. (2021, January 9). The best STEM subscription boxes for kids! Tried and True Creative blog. Retrieved from: https://www.triedandtrueblog.com/the-best-stemsubscription-boxes-for-kids/

Bruyere, B. L., Billingsley, E. D., \& O'Day, L. (2009). A closer examination of barriers to participation in informal science education for Latinos and Caucasians. Journal of Women and Minorities in Science and Engineering, 15(1).

Cabell, S. Q., Zucker, T. A., DeCoster, J., Copp, S. B., \& Landry, S. (2019). Impact of a parent text messaging program on pre-kindergarteners' literacy development. AERA Open, 5(1). https://doi.org/10.1177/2332858419833339

Caniglia, J., Meadows, M., Mupinga, D., \& Halas, K. (2021). Closing the achievement gap by bringing STEM kits home. National Science Teaching Association (NSTA) Science Scope. Retrieved from: https://www.nsta.org/science-scope/science-scope-mayjune2021/closing-achievement-gap-bringing-stem-kits-home

Caspe, M., Woods, T., \& Kennedy, J. L. (Eds.). (2018). Promising practices for engaging families in STEM learning. Charlotte, NC: Information Age Publishing.

Castro, M., Expósito-Casas, E., López-Martín, E., Lizasoain, L., Navarro-Asencio, E., \& Gaviria, J. L. (2015). Parental involvement on student academic achievement: A metaanalysis. Educational research review, 14, 33-46. https://doi.org/10.1016/j.edurev.2015.01.002

Clements, D. H., \& Sarama, J. (2008). Experimental evaluation of the effects of a researchbased preschool mathematics curriculum. American educational research journal, 45(2), 443-494. https://doi.org/10.3102/0002831207312908

Conezio, K., \& French, L. (2002). Science in the preschool classroom: Capitalizing on 
children's fascination with the everyday world to foster language and literacy development. Young children, 57(5), 12-18.

Deci, E. L., Koestner, R., \& Ryan, R. M. (1999). A meta-analytic review of experiments examining the effects of extrinsic rewards on intrinsic motivation. Psychological Bulletin, 125(6), 627-668. https://doi.org/10.1037/0033-2909.125.6.627

Degol, J. L., Wang, M. T., Ye, F., \& Zhang, C. (2017). Who makes the cut? Parental involvement and math trajectories predicting college enrollment. Journal of Applied Developmental Psychology, 50, 60-70. https://doi.org/10.1016/j.appdev.2017.03.007

Gelman, R., \& Brenneman, K. (2004). Science learning pathways for young children. Early Childhood Research Quarterly, 19(1), 150-158. https://doi.org/10.1016/j.ecresq.2004.01.009

Greenfield, D. B., Jirout, J., Dominguez, X., Greenberg, A., Maier, M., \& Fuccillo, J. (2009). Science in the preschool classroom: A programmatic research agenda to improve science readiness. Early Education and Development, 20(2), 238-264.

Grindal, T., Bowne, J. B., Yoshikawa, H., Schindler, H. S., Duncan, G. J., Magnuson, K., \& Shonkoff, J. P. (2016). The added impact of parenting education in early childhood education programs: A meta-analysis. Children and Youth Services Review, 70, 238-249. https://doi.org/10.1016/j.childyouth.2016.09.018

Haden, C. A. (2010). Talking about science in museums. Child Development Perspectives, 4(1), 62-67. https://doi.org/10.1111/j.1750-8606.2009.00119.x

Hurst, M. A., Polinsky, N., Haden, C. A., Levine, S. C., \& Uttal, D. H. (2019). Leveraging research on informal learning to inform policy on promoting early STEM. Social Policy Report, 32(3), 1-33. https://doi.org/10.1002/sop2.5

Jameson, M. M., \& Fusco, B. R. (2014). Math anxiety, math self-concept, and math selfefficacy in adult learners compared to traditional undergraduate students. Adult Education Quarterly, 64(4), 306-322. https://doi.org/10.1177/0741713614541461

Justice, L. M., Chen, J., Tambyraja, S., \& Logan, J. (2018). Increasing caregivers' adherence to an early-literacy intervention improves the print knowledge of children with language Impairment. Journal of Autism and Developmental Disorders, 48(12), 4179-4192. https://doi.org/10.1007/s10803-018-3646-2

Kaderavek, J. N., Paprzycki, P., Czerniak, C. M., Hapgood, S., Mentzer, G., Molitor, S., \& Mendenhall, R. (2020). Longitudinal impact of early childhood science instruction on 5th grade science achievement. International Journal of Science Education, 42(7), 1124 1143. https://doi.org/10.1080/09500693.2020.1749908

Kim, J. S., Asher, C. A., Burkhauser, M., Mesite, L., \& Leyva, D. (2019). Using a sequential multiple assignment randomized trial (SMART) to develop an adaptive $\mathrm{K}-2$ literacy intervention with personalized print texts and app-based digital activities. AERA Open, 5(3), 2332858419872701.

Leuchter, M., Saalbach, H., \& Hardy, I. (2014). Designing science learning in the first years of schooling. An intervention study with sequenced learning material on the topic of "floating and sinking." International Journal of Science Education, 36(10), 1751-1771. https://doi.org/10.1080/09500693.2013.878482

Levin, H. M., McEwan, P. J., Belfield, C., Bowden, A. B., \& Shand, R. (2017). Economic evaluation in education: Cost-effectiveness and benefit-cost analysis. (3rd ed.). SAGE publications.

Leyva, D., Tamis-LeMonda, C. S., Yoshikawa, H., Jimenez-Robbins, C., \& Malachowski, L. 
(2017). Grocery games: How ethnically diverse low-income mothers support children's reading and mathematics. Early Childhood Research Quarterly, 40, 63-76. https://doi.org/10.1016/j.ecresq.2017.01.001

Ma, X., Shen, J., Krenn, H. Y., Hu, S., \& Yuan, J. (2016). A meta-analysis of the relationship between learning outcomes and parental involvement during early childhood education and early elementary education. Educational Psychology Review, 28(4), 771-801. https://doi.org/10.1007/s10648-015-9351-1

Manolitsis, G., Georgiou, G. K., \& Tziraki, N. (2013). Examining the effects of home literacy and numeracy environment on early reading and math acquisition. Early Childhood Research Quarterly, 28(4), 692-703. https://doi.org/10.1016/j.ecresq.2013.05.004

McClure, E. R., Guernsey, L., Clements, D. H., Bales, S. N., Nichols, J., Kendall-Taylor, N., \& Levine, M. H. (2017). STEM starts early: Grounding science, technology, engineering, and math education in early childhood. New York: NY: The Joan Ganz Cooney Center at Sesame Workshop.

Milner-Bolotin, M., \& Marotto, C. C. (2018). Parental engagement in children's STEM education. Part I: Meta-analysis of the literature. LUMAT: International Journal on Math, Science and Technology Education, 6(1), 41-59.

Napoli, A. R., \& Purpura, D. J. (2018). The home literacy and numeracy environment in preschool: Cross-domain relations of parent-child practices and child outcomes. Journal of Experimental Child Psychology, 166, 581-603. https://doi.org/10.1016/j.jecp.2017.10.002

National Research Council. (2009). Learning science in informal environments: People, places, and pursuits. Washington, DC: National Academies Press.

National Research Council. (2015). Guide to implementing the next generation science standards. National Academies Press.

Nelson, A.G., Crowley, K., Pattison, S., Bailey, E. (2016) How young children learn science. The Center for Advancement of Informal Science Education (CAISE). https://www.informalscience.org/news-views/how-young-children-learn-science

Ness, D., \& Farenga, S. J. (2016). Blocks, bricks, and planks: relationships between affordance and visuo-spatial constructive play objects. American Journal of Play, 8(2), 201-227.

Neuman, S. B. (2017). The information book flood: Is additional exposure enough to support early literacy development?. Elementary School Journal, 118(1), 1-27.

Parker, S. L., Jimmieson, N. L., \& Techakesari, P. (2017). Using stress and resource theories to examine the incentive effects of a performance-based extrinsic reward. Human Performance, 30(4), 169-192. https://doi.org/10.1080/08959285.2017.1347174

Pattison, S., Svarovsky, G., Ramos-Montañez, S., Gontan, I., Weiss, S., Núñez, V., Corrie, P., Smith, C., \& Benne, M. (2020). Understanding early childhood engineering interest development as a family-level systems phenomenon: Findings from the head start on engineering project. Journal of Pre-College Engineering Education Research (J-PEER), 10(1), Article 6. https://doi.org/10.7771/2157-9288.1234

Reinhart, M., Bloomquist, D., Strickler-Eppard, L., Czerniak, C. M., Gilbert, A., Kaderavek, J., \& Molitor, S. C. (2016). Taking science home: Connecting schools and families through science activity packs for young children. School Science and Mathematics, 116(1), 316. https://doi.org/10.1111/ssm.12152

Robinson, K. \& Harris, A. L. (2014). The broken compass: Parental involvement with children's education. Massachusetts, Cambridge: Harvard University Press. 
Romance, N. R., \& Vitale, M. R. (2012). Science IDEAS: A research-based K-5 interdisciplinary instructional model linking science and literacy. Science Educator, 21(1), 1-11.

Sabol, T. J., Sommer, T. E., Sanchez, A., \& Busby, A. K. (2018). A new approach to defining and measuring family engagement in early childhood education programs. AERA Open, 4(3). https://doi.org/10.1177/2332858418785904

Sonnenschein, S., \& Sun, S. (2017). Racial/ethnic differences in kindergartners' reading and math skills: Parents' knowledge of children's development and home- based activities as mediators. Infant and Child Development, 26(5). https://doi.org/10.1002/icd.2010

Starkey, P., \& Klein, A. (2000). Fostering parental support for children's mathematical development: An intervention with Head Start families. Early Education and Development, 11(5), 659-680. https://doi.org/10.1207/s15566935eed1105_7

Wang, M. T., \& Degol, J. (2013). Motivational pathways to STEM career choices: Using expectancy-value perspective to understand individual and gender differences in STEM fields. Developmental Review, 33(4), 304-340. https://doi.org/10.1016/j.dr.2013.08.001

What Works Clearinghouse. (2021). What Works Clearinghouse Standards Handbook, Version 4.1.Washington, DC: U.S. Department of Education, Institute of Education Sciences, National Center for Education Evaluation and Regional Assistance. https://ies.ed.gov/ncee/wwc/handbooks

York, B. N., Loeb, S., \& Doss, C. (2019). One step at a time the effects of an early literacy text-messaging program for parents of preschoolers. Journal of Human Resources, 54(3), 537-566. https://doi.org/10.3368/jhr.54.3.0517-8756R 
Table 1

Overview of the Teaching Together STEM Program by Treatment Conditions

\begin{tabular}{|c|c|}
\hline Conditions & Description \\
\hline $\begin{array}{l}\text { Treatment A- } \\
\text { Core TT } \\
\text { STEM }\end{array}$ & $\begin{array}{l}\text { Six workshops and six family museum passes: } \\
\text { - Event } 1 \text { STEM Language: Parents were introduced to the overarching concept that you } \\
\text { can increase your child's curiosity about the world through rich conversations that include } \\
\text { asking open-ended questions and routinely explaining technical and scientific vocabulary. } \\
\text { - Event } 2 \text { Inquiry: Parents learned how to explore science concepts in everyday activities } \\
\text { and practice reasoning/inquiry (predictions, causality, experimentation). } \\
\text { - Event } 3 \text { Early Math: Parents learned how to integrate counting, number identification, } \\
\text { and comparison talk into everyday activities. } \\
\text { Event } 4 \text { Gather Data: Parents explored how to gather information as you interact with } \\
\text { their child to include counting, tallies, and charts as simple forms of data in daily life. } \\
\text { Event } 5 \text { Engineering: Parents were presented with ways to encouraging tinkering and } \\
\text { creative problem solving within playful activities and common household materials. } \\
\text { Event } 6 \text { Systems: Parents and children explored patterns and systems in the world (e.g., } \\
\text { seasons, plants, human body) and how parts work together in a larger system. }\end{array}$ \\
\hline & $\begin{array}{l}\text { Text messages with event reminders and } 24 \text { informational texts: } \\
\text { - Event reminders sent } 1 \text { week before and } 2 \text { days before event with location and time } \\
\text { - Strategy explanations sent } 1 \text { day and } 8 \text { days after event (e.g., tips for using parent } \\
\text { strategy; conversation starters linked to workshop theme) } \\
\text { - Activity video links sent } 4 \text { days and } 12 \text { days after event. Short text message invited parents } \\
\text { to click for a fun, informal learning activity using common household objects (not kits) }\end{array}$ \\
\hline $\begin{array}{l}\text { Treatment B - } \\
\text { Add Kits }\end{array}$ & $\begin{array}{l}\text { Nine bilingual STEM activity kits: } \\
\text { - Two science activities: ocean animals book and puzzle; animal life cycle book and } \\
\text { manipulatives (e.g., frog or butterfly life cycle) } \\
\text { - Four math activities: counting butterflies game with manipulatives, non-standard } \\
\text { measurement activities with links, tangrams activities, snail counting book with } \\
\text { manipulatives } \\
\text { Three engineering activities: design a boat, design balloon powered cars, vehicle building }\end{array}$ \\
\hline $\begin{array}{l}\text { Treatment C- } \\
\text { Add Rewards }\end{array}$ & $\begin{array}{l}\text { Opportunity for six reward payments } \\
\text { - } \$ 2.50 \text { reward payment if parent sent researchers a text message or photo related to any } \\
\text { learning activity they did recently with their child }\end{array}$ \\
\hline
\end{tabular}


Table 2

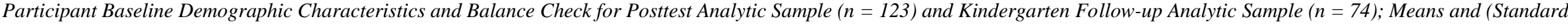
Deviations)

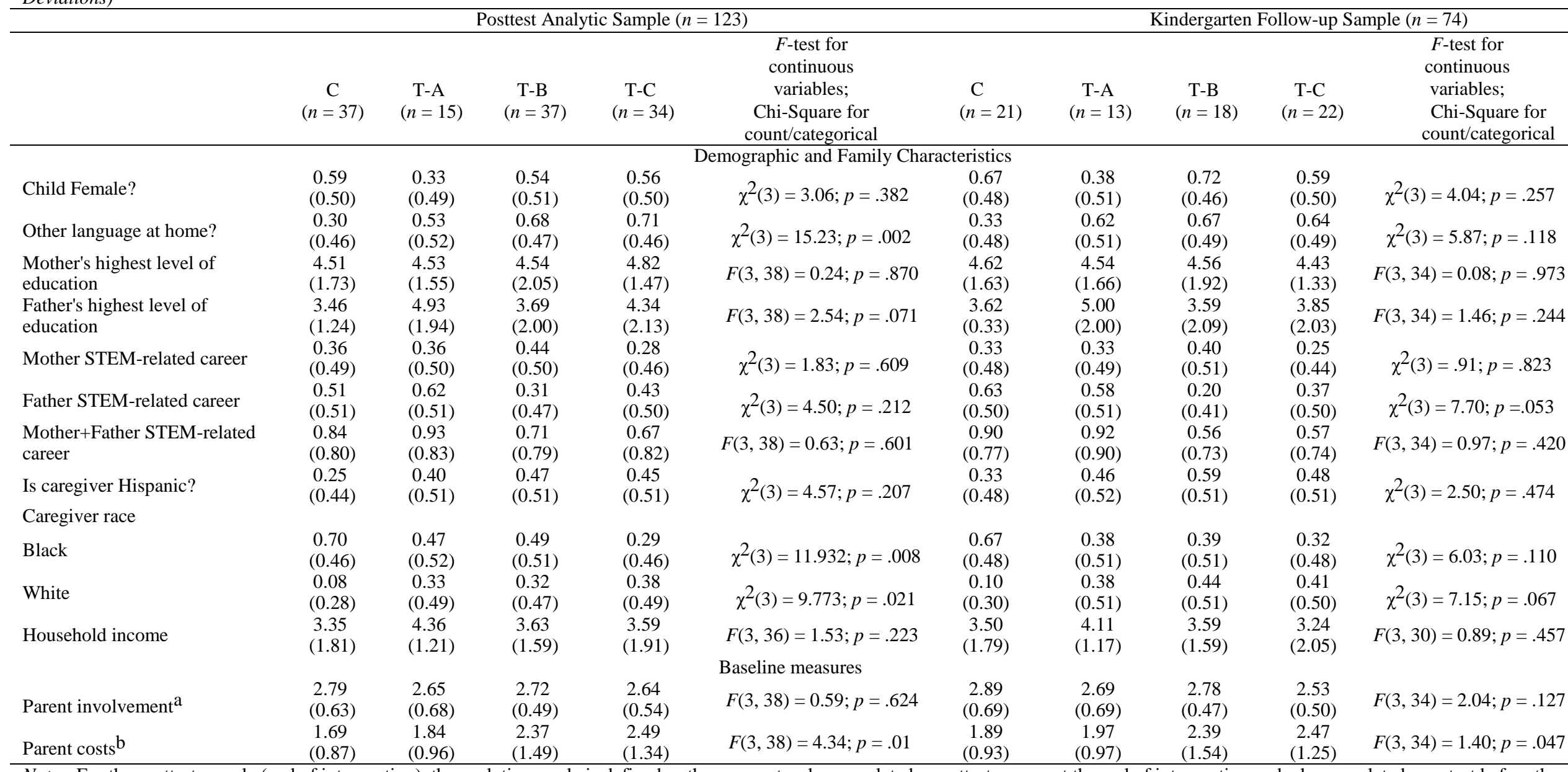

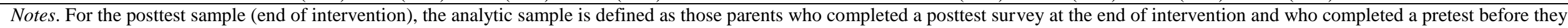

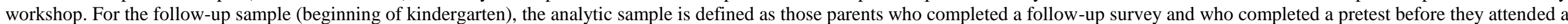
workshop. ${ }^{a}$ Ranges from $1=$ none to 4 everyday; ${ }^{b}$ Ranges from $1=$ not true at all/Strongly disagree to $7=$ Very true/Strongly agree.

$\mathrm{C}=$ Control; $\mathrm{T}-\mathrm{A}=$ Treatment A (Core Program); T-B =Treatment B (Add take home STEM kits); T-C: Treatment C (Add rewards) 
Table 3

\begin{tabular}{|c|c|c|c|c|}
\hline & \multicolumn{2}{|c|}{ Mean (SD) } & \multicolumn{2}{|c|}{$\begin{array}{l}\text { Percent of parents engaging } \\
\text { daily with these activities }\end{array}$} \\
\hline & Baseline & Posttest & Baseline & Posttest \\
\hline In the past week, number of times you talked to your child about shapes & $\begin{array}{c}3.04 \\
(0.80)\end{array}$ & $\begin{array}{r}2.99 \\
(0.88)\end{array}$ & $31.97 \%$ & $34.15 \%$ \\
\hline In the past week, number of times you compared sizes of different things with your child & $\begin{array}{r}2.90 \\
(0.79)\end{array}$ & $\begin{array}{c}2.85 \\
(0.92)\end{array}$ & $22.76 \%$ & $27.87 \%$ \\
\hline In the past week, number of times you counted different things with child & $\begin{array}{c}3.19 \\
(0.78)\end{array}$ & $\begin{array}{c}3.11 \\
(0.76)\end{array}$ & $39.02 \%$ & $33.33 \%$ \\
\hline In the past week, number of times you played counting games with your child & $\begin{array}{r}3.10 \\
(0.80)\end{array}$ & $\begin{array}{c}3.11 \\
(0.86)\end{array}$ & $36.07 \%$ & $38.52 \%$ \\
\hline In the past week, number of times you talked with your child about how to make things move & $\begin{array}{c}2.11 \\
(0.91)\end{array}$ & $\begin{array}{c}2.24 \\
(0.99)\end{array}$ & $8.13 \%$ & $13.01 \%$ \\
\hline In the past week, number of times you talked to your child about technology & $\begin{array}{r}2.44 \\
(0.92)\end{array}$ & $\begin{array}{c}2.71 \\
(0.96)\end{array}$ & $13.01 \%$ & $26.83 \%$ \\
\hline In the past week, number of times you talked with your child about weather/seasons & $\begin{array}{r}2.84 \\
(0.99)\end{array}$ & $\begin{array}{c}2.87 \\
(0.93)\end{array}$ & $30.08 \%$ & $32.52 \%$ \\
\hline In the past week, number of times that you talked with your child about nature-related topics & $\begin{array}{c}2.57 \\
(0.94)\end{array}$ & $\begin{array}{c}3.01 \\
(0.83)\end{array}$ & $18.85 \%$ & $33.33 \%$ \\
\hline In the past week, number of times that you talked with your child about health-related topics & $\begin{array}{r}3.06 \\
(0.89)\end{array}$ & $\begin{array}{r}3.30 \\
(0.83)\end{array}$ & $37.40 \%$ & $50.41 \%$ \\
\hline In the past week, number of times you played board/card games & $\begin{array}{c}1.84 \\
(0.87)\end{array}$ & $\begin{array}{c}2.02 \\
(0.87)\end{array}$ & $4.88 \%$ & $7.32 \%$ \\
\hline Literacy-related items (for comparison to STEM) & & & & \\
\hline In the past week, number of times you talked to your child about writing (ranges from 1-4) & $\begin{array}{r}3.06 \\
(0.81)\end{array}$ & $\begin{array}{r}3.00 \\
(0.80)\end{array}$ & $32.52 \%$ & $30.08 \%$ \\
\hline In the past week, number of times you read to your child (ranges from 1-4) & $\begin{array}{c}3.15 \\
(0.81)\end{array}$ & $\begin{array}{c}3.01 \\
(0.83)\end{array}$ & $38.21 \%$ & $32.52 \%$ \\
\hline In the past week, number of times you taught your child letters (ranges form 1-4) & $\begin{array}{r}3.06 \\
(0.81)\end{array}$ & Not asked & $49.59 \%$ & Not asked \\
\hline
\end{tabular}




\section{Table 4}

Main Impact Models Comparing Intervention Groups to Control Condition

\begin{tabular}{|c|c|c|c|c|c|c|c|c|c|c|c|c|c|c|c|}
\hline & \multicolumn{5}{|c|}{ Model 1} & \multicolumn{6}{|c|}{ Model 2} & \multicolumn{4}{|c|}{ Model 3} \\
\hline & ITT & $\begin{array}{l}\text { Robust } \\
\text { Standard } \\
\text { Error }\end{array}$ & $p$-value & TOT & $\begin{array}{c}\text { Effect } \\
\text { Size } \\
\text { for } \\
\text { TOT }\end{array}$ & ITT & $\begin{array}{c}\text { Robust } \\
\text { Standard } \\
\text { Error }\end{array}$ & $p$-value & TOT & $\begin{array}{c}\text { Effect } \\
\text { Size } \\
\text { for } \\
\text { TOT }\end{array}$ & ITT & $\begin{array}{l}\text { Robust } \\
\text { Standard } \\
\text { Error }\end{array}$ & $p$-value & TOT & $\begin{array}{c}\text { Effect } \\
\text { Size } \\
\text { for } \\
\text { TOT }\end{array}$ \\
\hline \multicolumn{16}{|c|}{ Posttest (end of pre-k intervention), $n=123$} \\
\hline Tx A & -0.15 & 0.18 & 0.419 & -0.36 & -0.57 & -0.09 & 0.17 & 0.594 & -0.23 & -0.36 & 0.00 & 0.17 & 0.989 & -0.01 & -0.01 \\
\hline Tx B & -0.25 & 0.15 & 0.095 & -0.39 & -0.61 & -0.19 & 0.15 & 0.229 & -0.29 & -0.46 & -0.03 & 0.13 & 0.802 & -0.05 & -0.08 \\
\hline Tx C & -0.16 & 0.11 & 0.161 & -0.29 & -0.46 & -0.07 & 0.11 & 0.529 & -0.13 & -0.20 & 0.07 & 0.12 & 0.583 & 0.12 & 0.18 \\
\hline \multicolumn{16}{|c|}{ Follow-up (beginning of Kindergarten), $n=74$} \\
\hline Tx A & -0.29 & 0.15 & 0.063 & -0.63 & -0.94 & -0.09 & 0.17 & 0.586 & -0.20 & -0.30 & -0.29 & 0.18 & 0.108 & -0.63 & -0.94 \\
\hline Tx B & -0.15 & 0.21 & 0.484 & -0.24 & -0.36 & -0.05 & 0.23 & 0.830 & -0.08 & -0.12 & 0.14 & 0.19 & 0.478 & 0.23 & 0.34 \\
\hline Tx C & -0.07 & 0.16 & 0.678 & -0.10 & -0.15 & 0.00 & 0.20 & 0.986 & 0.01 & 0.01 & 0.00 & 0.18 & 0.987 & 0.00 & -0.01 \\
\hline Adjusting for pre-test & & & Yes & & & & & Yes & & & & & Yes & & \\
\hline Adjusting for family-level variables & & & No & & & & & Yes & & & & & Yes & & \\
\hline Adjusting for school-level variables & & & No & & & & & No & & & & & Yes & & \\
\hline
\end{tabular}

Note. Control condition is the reference value. Tx A = Basic Program; Tx B = Basic Program + added kits; Tx C = Basic Program + added kits + rewards. ITT = Intent to Treat; TOT $=$ Treatment-on-the-treated.

${ }^{+} p<.10 ;{ }^{*} p<.05 ;{ }^{* *} p<.01 ;{ }^{* * *} p<.001$ 
Table 5

Main Impact Models with Alternative Reference Values

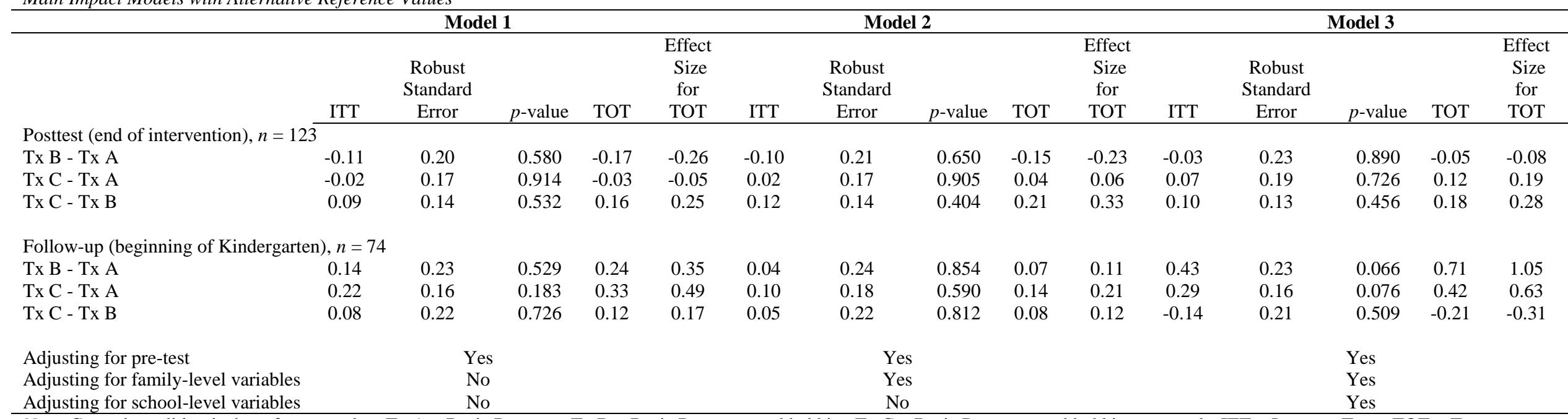

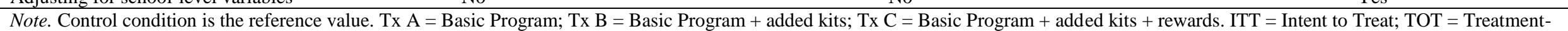
on-the-treated.

$+p<.10 ; * p<.05 ; * * p<.01 ; * * * p<.001$ 
Table 6

School-Based Parent Involvement: Attendance at TT STEM Events $(n=137$ parents with attendance $)$

\begin{tabular}{|c|c|c|c|c|c|c|}
\hline & $\begin{array}{l}\text { Group 0: } \\
\text { Attended } 0 \% \\
\text { of meetings } \\
(n=60)\end{array}$ & $\begin{array}{c}\text { Group 1: } \\
\text { Attended }>0 \% \\
\text { and }<=25 \% \\
(n=22)\end{array}$ & $\begin{array}{c}\text { Group 2: } \\
\text { Attended } \\
>25 \% \\
\text { and <= } \\
50 \% \\
(n=24)\end{array}$ & $\begin{array}{c}\text { Group 3: } \\
\text { Attended } \\
>50 \% \\
\text { and }<=75 \% \\
(n=16)\end{array}$ & $\begin{array}{l}\text { Group 4: } \\
\text { Attended } \\
>75 \% \\
(n=15) \\
\end{array}$ & Kruskal-Wallis test \\
\hline Mother's highest education & $4.43(1.63)$ & $4.67(1.62)$ & $3.88(1.62)$ & $4.86(1.92)$ & $4.73(2.05)$ & $\chi^{2}(d f=4)=5.14, p=.273$ \\
\hline Father's highest education* & $4.15(1.76)$ & $4.20(1.77)$ & $3.17(1.61)$ & $4.71(2.70)$ & $5.29(2.40)$ & $\chi^{L}(d f=4)=10.39, p=.034$ \\
\hline Mother STEM related & $0.33(0.48)$ & $0.35(0.49)$ & $0.26(0.45)$ & $0.50(0.52)$ & $0.13(0.35)$ & $\chi^{2}(d f=4)=4.96, p=.291$ \\
\hline Father STEM related & $0.39(0.49)$ & $0.29(0.47)$ & $0.45(0.51)$ & $0.64(0.50)$ & $0.36(0.50)$ & $\chi^{2}(d f=4)=4.42, p=.352$ \\
\hline Home Language other than English & $0.48(0.50)$ & $0.43(0.51)$ & $0.71(0.46)$ & $0.60(0.51)$ & $0.73(0.46)$ & $\chi^{2}(d f=4)=6.88, p=.143$ \\
\hline Is caregiver Hispanic? & $0.33(0.48)$ & $0.30(0.47)$ & $0.48(0.51)$ & $0.53(0.52)$ & $0.40(0.51)$ & $\chi^{2}(d f=4)=3.48, p=.481$ \\
\hline \multicolumn{7}{|l|}{ Caregiver's race } \\
\hline Black & $0.55(0.50)$ & $0.57(0.51)$ & $0.29(0.46)$ & $0.40(0.51)$ & $0.33(0.49)$ & $\chi^{L}(d f=4)=6.85, p=.144$ \\
\hline White $^{+}$ & $0.21(0.41)$ & $0.24(0.44)$ & $0.38(0.49)$ & $0.47(0.52)$ & $0.53(0.52)$ & $\chi^{L}(d f=4)=9.04, p=.060$ \\
\hline Household Income & $3.46(1.88)$ & $3.28(1.45)$ & $3.24(1.81)$ & $4.08(2.10)$ & $3.92(1.44)$ & $\chi^{2}(d f=4)=2.58, p=.631$ \\
\hline Treatment A & $0.32(0.47)$ & $0.27(0.46)$ & $0.29(0.46)$ & $0.13(0.34)$ & $0.13(0.35)$ & $\chi^{2}(d f=4)=3.85, p=.427$ \\
\hline Treatment B & $0.35(0.48)$ & $0.50(0.51)$ & $0.29(0.46)$ & $0.50(0.52)$ & $0.67(0.49)$ & $\chi^{2}(d f=4)=7.53, p=.110$ \\
\hline Treatment $\mathrm{C}$ & $0.33(0.48)$ & $0.23(0.43)$ & $0.42(0.50)$ & $0.38(0.50)$ & $0.20(0.41)$ & $\chi^{2}(d f=4)=3.13, p=.536$ \\
\hline Parental Involvement at pretest & $2.68(0.58)$ & $2.72(0.55)$ & $2.62(0.65)$ & $2.57(0.55)$ & $2.53(0.36)$ & $\chi^{2}(d f=4)=1.89, p=.756$ \\
\hline Parental Costs at pretest & $2.13(1.31)$ & $1.81(1.00)$ & $2.74(1.49)$ & $2.71(1.56)$ & $2.07(0.75)$ & $\chi^{2}(d f=4)=7.72, p=.102$ \\
\hline School Support at pretest & $6.09(1.22)$ & $6.26(0.86)$ & $5.92(1.30)$ & $6.23(1.28)$ & $6.40(0.91)$ & $\chi^{2}(d f=4)=2.30, p=.681$ \\
\hline Percent of time school staff attended workshop & $0.29(0.26)$ & $0.35(0.26)$ & $0.47(0.34)$ & $0.32(0.32)$ & $0.40(0.25)$ & $\chi^{2}(d f=4)=7.51, p=.111$ \\
\hline
\end{tabular}

Note. $+p<.10 ; * p<.05 ; * * p<.01 ; * * * p<.001$ 